\title{
A BANCADA DOS JÚNIOR(ES): FAMÍLIAS E PARENTESCO NO LEGISLATIVO PARANAENSE DURANTE O GOVERNO BETO RICHA $^{1}$
}

\author{
Eduardo Soncini Miranda ${ }^{2}$
}

- Enviado em 18/04/2016

- Aprovado em 20/05/2016

\section{RESUMO}

Investigamos a estrutura de poder e seus respectivos agentes políticos materializada na identificação das relações de parentesco e ocupação de cargos estratégicos dentro do Governo do Paraná, em especial nas secretarias de Estado e na Assembleia Legislativa do Paraná. Nesse sentido, buscamos explicitar as relações de interesse envolvendo, sobretudo, parlamentares e cargos políticos no aparelho de Estado (executivo, legislativo e judiciário), buscando assegurar vantagens e privilégios (sociais, econômicos e eleitorais) para esses participantes. Através da análise do perfil sociológico, das trajetórias políticas e dos cargos ocupados pelos atores e dados eleitorais afim de identificar situações de privilégio/destaque no que tange a relação de parentesco e ocupação de cargos estratégicos dentro do aparelho do Estado. Por fim, analisamos as trajetórias e conexões entre as famílias dos principais atores envolvidos dentro dessa complexa teia de interesses e resgataremos as origens históricas desses desdobramentos.

Palavras-chave: Parentesco, Paraná, Parlamentares

\section{INTRODUÇÃO}

Acreditamos que o estudo das relações entre as famílias e o Estado é imprescindível para a análise da política paranaense. Nesse sentido buscaremos desde logo estabelecer as conexões entre as principais instituições que formam a atual estrutura do Estado Paranaense, seus ocupantes e suas

\footnotetext{
${ }^{1}$ Uma versão preliminar desse trabalho foi apresentada no GT1: INSTITUIÇÕES E PODER: PARENTESCOS E GENEALOGIAS do VII Seminário Nacional de Sociologia e Política da UFPR realizado de 11 a 13 de maio de 2016 em Curitiba.

${ }^{2}$ Doutorando em Ciência Política/UFPR. eduardomiranda@ufpr.br
} 
genealogias/famílias visando revelar/estabelecer apontamentos relações e críticas ao seu funcionamento e pertinência.

Diversos trabalhos acadêmicos se debruçaram sobre as formações das famílias históricas no Brasil, suas genealogias e relações com a formação do Estado Brasileiro (FREIRE, 1933; HOLANDA, 1936; FAORO, 1958). Alguns clássicos mapearam essas conexões. Cito como exemplo/referência algumas obras voltadas aos estudos dessa temática no Estado do Paraná como os livros: Genealogia Paranaense de Francisco Negrão (1946) e O Silencio dos Vencedores. Genealogia, classe dominante e Estado no Paraná de Ricardo Oliveira (2001) ${ }^{3}$

Para além dos trabalhos mencionados (todos lançam mão de extensa e profunda análise das relações de parentesco e o Estado nos mais diversos e importantes períodos de nossa história política: Colônia, República, Ditadura Militar, Democracia) buscamos neste artigo trazer o debate para o cenário atual (Governo Beto Richa/2016) resgatando sua importância para a análise do caso paranaense questionando e colocando luz sobre a atualidade das conexões entre as famílias e o funcionamento do Estado Brasileiro.

Ao contrário do que se poderia imaginar, durante a Redemocratização do País (1985 em diante) não houve no Paraná grandes rupturas/mudanças tanto do ponto de vista dos nomes/famílias (ocupantes dos principais cargos públicos), quanto do ponto de vista das próprias instituições (suas estruturas internas, regimentos, prerrogativas, entre outros).

As eleições de 1982 apresentaram ao Paraná uma nova janela de oportunidade para que novas famílias políticas se formassem e ocupassem o centro do poder político no Estado para logo após fecharem-se e se revezarem no poder perdurando por pelo menos 30 anos, até os dias de hoje. (OLIVEIRA, 2012). Nesse sentido, as novas famílias Dias e Richa ganharam destaque e somaramse as já atuantes famílias Mello e Silva e Lerner que representam tradições mais antigas - a última ligado ao Neysmo (Ney Braga). Portanto é sintomático que cheguemos ao ano de 2016 e analisemos o resultado das últimas eleições no Paraná cravando Beto Richa como governador do Estado (2014) e Gustavo Fruet como prefeito de Curitiba (2012). Ambos filhos de políticos que ocupavam os mesmos postos de seus respectivos pais há cerca de 30 anos atrás: o ex governador Jose Richa e o ex prefeito da capital Mauricio Fruet.

O que há de novo na atualidade, em nossa ótica, é uma maior facilidade de acesso a dados e a justiça/leis de uma maneira geral, sobretudo devido ao fortalecimento de instituições como a Polícia e Ministério Público e aos avanços das novas tecnologias, blogs e os portais de

\footnotetext{
${ }^{3}$ Para além das obras supracitadas há em destaque a atuação do Grupo de Estudos Paranaenses (NEP/UFPR) que por mais de duas década reúne pesquisadores que se dedicam ao tema, promovendo eventos e publicações nesse sentido.
} 
transparência. Assim, o monitoramento e a revelação das conexões se torna mais fácil do ponto de vista metodológico da coleta de dados e altamente necessária do ponto de vista da relevância. Essa pesquisa ajuda a denunciar/identificamos que hoje a sociedade civil e a imprensa livre por vezes fazem o papel de fiscalização, prerrogativa de instituições, partidos políticos e seus agentes que muitas vezes a negam por conexões políticas, conluios e interesses mútuos. Esse artigo busca contribuir desvendando esses dados e procurando suprir essa lacuna.

Concluímos que a constatação do grande número de relações entre famílias e poderes presentes hoje no Paraná - muitas delas seculares e na esteira da ilegalidade (vide os casos de corrupção citados abaixo), sua contínua ocorrência e permissividade - impacta de maneira significativamente negativa o funcionamento do Estado no Paraná. (A independência entre os poderes, a transparência, os resultados eleitorais, o princípio da impessoalidade, a neutralidade nos julgamentos do poder judiciário, enfim as políticas públicas).

\section{PODER EXECUTIVO}

O principal cargo do poder executivo municipal e estadual é ilustrativo e serve de ponto de partida de nossa análise, mas buscaremos ampliá-la na medida em que estudamos nessa pesquisa também os poderes legislativo e judiciário.

No dia 03 de outubro de 2010 o candidato Beto Richa (PSDB) foi eleito governador do Paraná no primeiro turno daquelas eleições. Richa recebeu 3.039.774 de votos, o que equivale a $52,43 \%$ do total de votos válidos segundo o Tribunal Superior Eleitoral (TSE), seu opositor era Osmar Dias (PDT) que teve 2.645.341 votos, $45,63 \%$ dos votos válidos. ${ }^{4}$ À época Osmar Dias era Senador pelo Paraná. O primeiro cargo público de Osmar Dias foi como presidente da Companhia Agropecuária de Fomento Econômico do Estado do Paraná, entre 1983 e 1986, durante o governo José Richa (pai de Beto Richa). Em seguida, Osmar foi secretário da agricultura do Paraná entre 1987 e 1994 na gestão dos governadores Álvaro Dias (seu irmão) e Roberto Requião. Em 1994 foi eleito senador do Paraná pelo partido Progressista (PP). Filiou-se em seguida ao PSDB, chegando a ocupar a vice-liderança na Casa. Osmar Dias é irmão de Álvaro Dias (atual senador e ex

\footnotetext{
${ }^{4}$ Osmar Dias, antes do início da campanha, chegou a ser assediado pelos tucanos para se candidatar ao Senado. No prazo final das convenções, Osmar Dias decidiu aceitar o convite para se candidatar ao governo estadual na coligação do PT/PMDB após ter garantias de apoio do presidente Luiz Inácio Lula da Silva para a campanha no estado. Lula, de fato, esteve no estado e subiu no palanque de Osmar Dias.
} 
governador) que até muito recentemente era um dos nomes mais fortes do PSDB nacional e consequentemente da oposição ao governo Dilma (PT). Seu irmão Osmar é atualmente filiado ao PDT partido da base de apoio da presidente Dilma e ocupa o cargo de vice-presidente de Agronegócios e Micro e Pequenas Empresas do Banco do Brasil desde 2011. A família Dias proporciona ao analista uma importante e curiosa constatação: o Paraná é/foi único Estado da história do Brasil a possuir dois senadores irmãos na mesma legislatura dos três senadores da república pelo Estado.

Carlos Alberto Richa - Beto Richa - se reelegeu governador do Paraná no dia 05 de outubro de 2014, derrotando o senador/ex-governador Roberto Requião de Mello e Silva (PMDB) e a senadora/ex-ministra da Casa Civil Gleisi Hoffmann (PT). O candidato do PSDB venceu a disputa com 3.301 .322 votos, o que equivale a $55,67 \%$ dos votos válidos, contra 1.634 .316 votos - 27,56\% do peemedebista e 881.857 votos $-14,87 \%$ da petista. Na disputa pela vaga do Estado paranaense no Senado, o vencedor foi o também tucano Álvaro Dias, reeleito para mais um mandato de oito anos.

O atual chefe do poder executivo estadual é em si é a personificação das tradições, das relações entre famílias e Estado e do modus operandi desse modelo aqui a ser explorado. Beto Richa é filho de José Richa - descendente de imigrantes libaneses e que também já havia sido governador do Paraná, eleito em 1982 nas primeiras eleições diretas desde 1964 - José Richa também havia sido prefeito de Londrina, deputado e senador da República. José Richa entrou na política pelas mãos de Ney Braga e antes de morrer deixou seu filho Beto Richa como herdeiro político $^{5}$ (OLIVEIRA, 2007)

Beto Richa é formado em Engenharia Civil pela PUC-PR, sua primeira disputa eleitoral foi em 1992 quando não se elegeu vereador por Curitiba. Em 1994, foi eleito deputado estadual com 22 mil votos e reeleito quatro anos mais tarde com o dobro de votos 44.838 . Também foi vice-prefeito de Curitiba na gestão de Cassio Taniguchi e, em 2002, candidatou-se ao governo do Estado do Paraná pelo PSDB, ficando em terceiro lugar numa disputa contra Osmar Dias e Roberto Requião de Mello e Silva (ganhador). Em 2004, elegeu-se prefeito de Curitiba com 494.440 mil votos e em 2010, em 2008 foi reeleito prefeito de Curitiba com 778.514 mil votos (77\% do total), renunciou ao segundo mandato de prefeito para concorrer e ser eleito governador do Paraná.

Beto Richa é casado com Fernanda Bernardi Andrade Vieira, atual secretária do trabalho e desenvolvimento social do Paraná (pasta recentemente redimensionada por uma reforma

\footnotetext{
${ }^{5}$ Ver mais detalhes em http://dx.doi.org/10.1590/S1517-45222007000200008
} 
administrativa no secretariado passando a receber mais recursos e cargos de confiança para as políticas sociais/assistenciais e repasses do bolsa família). Fernanda é bacharel em Direito e filha de Tomas Edson Andrade Vieira, um dos mais importantes banqueiros do Brasil na década de 1970, falecido em um acidente aéreo. Tomas Edson, por sua vez, é filho do fundador e comandante do grupo Bamerindus Avelino Antonio Vieira. Avelino nasceu em Tomazina, no norte pioneiro do Paraná em 03.11.1905, ele é filho dos imigrantes libaneses Miguel Antoun e Cecília Bernardina da Silva. Avelino era comerciante e participou da fundação de uma empresa bancária em 1929 (ano da queda da bolsa de Nova York) que daria origem ao Banco Bamerindus. Foi prefeito de Tomazina e deputado estadual (1947-1950). A genealogia de Fernanda Bernardi Andrade Vieira Richa vem de famílias latifundiárias, como a família Junqueira $(\mathrm{MG})$ e do Barão de Lavras. "Uma família de origem imigrante alcançando o poder contrai matrimônios com velhas famílias estabelecidas do status quo $"$ (OLIVEIRA, 2015).

Outro nome importante da família é José Eduardo de Andrade Vieira, nascido em Tomazina, em 1938, faleceu em 2015. Foi senador pelo Paraná (1991-1999) e ministro nos governos de Itamar Franco e Fernando Henrique Cardoso (FHC). No primeiro governo, comandou o ministério da Indústria, do Comércio e do Turismo (1992-1993) e, posteriormente, assumiu a Agricultura, Abastecimento e Reforma Agrária (1993). Durante o período FHC, voltar a chefiar a Agricultura (1995-1996). Entre 1981 e 1997, presidiu Bamerindus, banco fundado por sua família e que foi vendido ao HSBC. Em 1992, ele se tornou sócio da Folha de Londrina (atual Grupo de Comunicação e Portal Bonde) e assumiu a superintendência do jornal em 1999. Quando teve início o seu primeiro mandato, Jose Eduardo tinha uma fortuna avaliada em 200 milhões de dólares, sendo o controlador do terceiro maior banco privado do país - o Bamerindus. Perdeu o banco - a política do Banco Central à época era de desnacionalização da economia brasileira (PEREIRA, 2006) ${ }^{7} \mathrm{e}$ como um dos principais arrecadadores das campanhas de Fernando Henrique Cardoso e do PSDB do Paraná, acusou o desvio de mais de R\$ 100 milhões para o exterior. "Andrade Vieria diz que o PSDB teve uma sobra de R\$130 milhões na campanha de 1994 e que esse dinheiro foi para o exterior, 8

\footnotetext{
${ }^{6}$ Trecho extraído do artigo de Ricardo Oliveira intitulado Famílias Políticas, Desigualdade e Estratificação Social no Brasil Contemporâneo apresentado na oportunidade do XVII Congresso Brasileiro de Sociologia em Porto Alegre em 2015.

${ }^{7}$ PEREIRA, Thulio C. G. Bancos e banqueiros, sociedade e política: o Bamerindus e José Eduardo de Andrade Vieira (1981 a 1994). Tese (Doutorado). Florianópolis: Universidade Federal de Santa Catarina, Programa de Pós-Graduação em Sociologia Política, 2006.
}

${ }^{8}$ Revista Veja. Edição 1662 de 16 de agosto de 2000. Disponível em veja.abril.com.br/160800/p_038.html 
Um dos três filhos do casal Beto Richa e Fernanda Richa é Marcelo Richa, ele é o atual presidente do Instituto Teotônio Villa, Marcelo já foi presidente da Juventude do PSDB e secretário municipal do esporte e da juventude de Curitiba na gestão do prefeito Luciano Ducci, aliado do Governador Beto Richa, que durante sua gestão também nomeou a tia de Fernanda Richa, Maria Christina Andrade Vieira, para a presidência da Fundação Cultural de Curitiba.

Além da esposa, um dos irmãos de Beto Richa, José Richa Filho, é hoje secretário de infraestrutura e logística do Paraná (pasta responsável pelas obras em portos, aeroportos, estradas, pelo pedágio e repasses do PAC). Pepe Richa, como é conhecido, já foi secretário de administração da Prefeitura de Curitiba e, antes, foi diretor-financeiro do Departamento de Estradas de Rodagem do Governo do Paraná na gestão de Jaime Lerner, ocupou cargos na Agência de Fomento, no Governo Requião em 2003. Outro filho do falecido ex-Governador José Richa é Adriano Richa, que ganhou cartório na Região Metropolitana de Curitiba ainda na época em que o pai era vivo. O avô materno de Beto Richa, Adhemar Vilela, foi presidente da Câmara de Vereadores de Jandaia do Sul nos anos 60.

Figuram ainda no primeiro escalão do governo Beto RICHA o primo Marcos Traad, no DETRAN e o primo "distante" Luiz Abi Antoun, que foi preso em um escândalo de licitações públicas e é citado na Operação Publicano que investiga fraudes na receita estadual. Antoun foi preso em março de 2015, acusado de corrupção em oficinas de conserto de carros - a operação Voldemort do Grupo Especial de Combate a Crime Organizado (GAECO). A esposa de Antoun Eloiza Antoun ${ }^{9}$ e a primeira dama Fernanda Richa foram sócias de uma faculdade privada. Dois filhos de Antoun: Kouthar e Nemer Abi Antoun são sócios da empresa KLM Brasil com sede em Cambé. Essa empresa doou dinheiro a campanha de outro primo de Beto Richa, Gustavo Richa (PHS), que foi o sexto vereador mais votado dos 19 de Londrina, em 2014 Gustavo disputou uma vaga de deputado estadual sem êxito.

$\mathrm{O}$ vice prefeito de Cascavel na gestão de Edgar Bueno ${ }^{10}$ é Mauricio Querino Theodoro que é concunhado de Luiz Abib Antoun. Ele é casado com Maria Fernandes Pinheiro, irmã de Eloisa Fernandes Pinheiro Abi Antoun - esposa de Luiz Abib Antoun. Anteriormente Maurício já vinha ocupando cargos de destaque no Governo como as diretorias da Sercomtel e Ferroeste. Identificamos também a nomeação de Ines Fernades Pinheiro, irmã de Eloisa e portanto cunhada de Antoun na SEDU em 2011 lotada em um cargo de direção DAS-5.

\footnotetext{
${ }^{9}$ Eloiza Antoun foi diretora de participações na Sercomtel.

${ }^{10}$ Edgar Bueno é pai do deputado estadual Andre Bueno.
} 
A vice governadora do Paraná Cida Borghetti, segue o modus operandi do Governador e também demostra em si a personificação da questão aqui levantada. Cida é casada com o deputado federal Ricardo Barros e é mãe da deputada estadual Maria Victória Borghetti Barros, cunhada do ex secretário de planejamento e prefeito de Maringá Silvio Barros e irmã de Juliano Borghetti ex vereador (preso recentemente em uma briga de torcidas de futebol e recentemente casado com Renata Bueno - filha de Rubens Bueno PPS).

Após a análise da governadoria e da vice governadoria no Paraná passamos o foco às secretarias que compõem o governo. Atualmente há no Paraná 17 secretárias e duas secretarias especiais: a de assuntos estratégicos (1) e de relações institucionais e relacionamento (2). A maioria das secretarias é chefiada por políticos experientes do Paraná, que trazem consigo as conexões aqui discutidas. As duas secretarias especiais também são chefiadas por pessoas de famílias tradicionais e com relações de parentesco. Apresentaremos algumas delas a fim de demonstrar o modus operandi desse modelo. Comecemos pela Casa Civil.

\begin{tabular}{|c|c|}
\hline Secretaria & Nome \\
\hline Casa Civil & Valdir Luiz Rossoni \\
\hline Secretaria da Administração e da Previdência & Reinold Stephanes \\
\hline Secretaria da Agricultura e do Abastecimento & Norberto Anacleto Ortigara \\
\hline Secretaria da Ciência, Tecnologia e Ensino Superior & Joao Carlos Gomes \\
\hline \multicolumn{2}{|l|}{ Secretaria da Comunicação Social } \\
\hline Secretaria da Cultura & João Luiz Fiani \\
\hline Secretaria do Desenvolvimento Urbano & Ratinho Jr \\
\hline Secretaria da Educação & Ana Seres Comim \\
\hline Secretaria do Esporte e do Turismo & Douglas Fabrício \\
\hline Secretaria da Fazenda & Mauro Ricardo \\
\hline Secretaria da Infraestrutura e Logística & José Richa Filho (Pepe) \\
\hline Secretaria da Justiça, Cidadania e Direitos Humanos & Artagão de Mattos Leão \\
\hline Secretaria do Meio Ambiente e Recursos Hídricos & Ricardo José Soavinski \\
\hline Secretaria do Planejamento e Coordenação Geral & Sílvio Barros \\
\hline Secretaria da Saúde & Michelle Caputo \\
\hline Secretaria da Segurança Pública e Administração Penitenciária & Wagner Mesquita \\
\hline Secretaria do Trabalho e Desenvolvimento Social & Fernanda Richa \\
\hline Secretaria para Assuntos Estratégicos & Flavio Arns \\
\hline Secretaria Relações Institucionais e Cerimonial & Ezequias Moreira \\
\hline
\end{tabular}

Há um certo consenso dentro da ciência política brasileiro que o mais importante cargo dos secretariados para nível estadual, vale também para os ministérios, nível federal, é a chefia da casa civil. O Paraná não é exceção e por aqui, também não por acaso, essa secretaria é altamente disputada por pesos pesados de nossa política. Atualmente o chefe da Casa Civil é o deputado 
federal Valdir Luiz Rossoni (PSDB). Rossoni nasceu em Bituruna/PR em 1952. Empresário do ramo do agronegócio e madeireiras. Rossoni é formado em Matemática pela Universidade Estadual de Ponta Grossa (UEPG). Em 1978 foi nomeado secretario de administração da prefeitura de Bituruna. Em 1982 se elegeu prefeito de Bituruna ${ }^{11}$. Entre 85/86 foi presidente da Associação dos municípios do sul do Paraná (Amsulpar). Deputado Estadual pelo PRN (91-99), PDT (99-03), PTB (03-07), PSDB (07-11). Em 2014 foi o terceiro deputado federal mais votado do Paraná com mais de 170 mil votos. Bituruna aliás teve uma prefeita eleita cassada recentemente , a candidatura de Catiane Rossoni (nora do deputado Valdir Rossoni) teve o registo de sua candidatura cassado. De acordo com a Justiça Eleitoral ela comprovou filiação partidária em tempo hábil de concorrer às eleições, Catiane é esposa de Rodrigo Rossoni ex prefeito de Bituruna, que teve o mandato cassado em março de 2012 por abuso de poder econômico.

Passando para as demais pastas encontramos relações de Parentesco entre seus chefes e demais poderes do Estado em mais da metade do secretariado atual do Governador Beto Richa (na tabela em azul). Nesse sentido, a secretaria de Planejamento, uma das principais pastas já que é a responsável por definir as peças orçamentarias e o plano plurianual, enfim, por pensar o futuro das políticas públicas e elaboração dos orçamentos para tanto é chefiada por Silvio Barros. Silvio Barros II é ex prefeito de Maringá e cunhado da vice governadora Cida Borghetti, irmão do deputado federal Ricardo Barros (relator do orçamento no governo Dilma), tio da deputada estadual Maria Victoria Barros e concunhado de Juliano Borghetti ex vereador de Curitiba preso recentemente. Seu pai, também chamado Silvio Barros já havia sido prefeito de Maringá

$\mathrm{Na}$ secretaria de Administração e Previdência figura umas das pessoas mais tradicionais e que literalmente passou pelas mais diversas administrações do ponto de vista político - estamos falando de Rheinold Stephanes. Nasceu em 1939 em Porto Uniao/SC. Economista e professor universitário. Filho de Oswald Stephanes e Lili Pohl. Deputado Federal 1979 pela ARENA. Foi Assessor Econômico do Departamento de Fazenda da Prefeitura de Curitiba em 1964. Supervisor de Planejamento Econômico e Social, Gabinete do Prefeito de Curitiba, 1965. Professor Universitário na PUC/PR 1966/1967 e secretário municipal da fazenda entre 66/67. Diretor Geral e Inspetor da Fazenda 67-70. Subecretario de Planejamento e Orçamento do Ministério da Agricultura 70-73. Diretor do INCRA 70-73. Secretario de Apoio do MEC 74. Presidente do INPS, 74-79. Secretário de Agricultura 79-83. Ministro do Trabalho e Previdência Social 92. Ministro da Previdência 95-98. Presidente do Banco do estado do Paraná 92-2000. Secretario de Administração do Paraná 2003-

\footnotetext{
${ }^{11}$ Bituruna teve destaque nos noticiários em 2016. A empresa Valor te sede na cidade e aparece na Operação Quadro Negro que investiga desvios de dinheiro público de construção e reformas de escolas no Paraná 
2004. Secretario de Planejamento 2004-2006. Ministro da Agricultura, pecuária e Abastecimento 2007-2010. Foi do PSD, ARENA, PFL, PMDB, PSD. É pai do atual deputado estadual Reinold Stephanes Junior (PMDB), ex vereador de Curitiba.

Na secretaria de Justiça encontramos o atual secretário Artagão Júnior que é ex deputado estadual e filho do conselheiro do Tribunal de Contas Artagão de Mattos Leão.

Nas duas secretarias especiais não é diferente. Em uma encontra-se Flavio Arns e na outra Ezequias Moreira. Arns nasceu em Curitiba em 1950, formado em Letras e Direito. Ex deputado federal é ex senador ex secretário de educação e vice governador no primeiro mandato de governador de Beto Richa. É sobrinho do Cardeal Arcebispo de São Paulo Dom Evaristo Arns e sobrinho de Zilda Arns, médica fundadora da Pastoral das Crianças.

$\mathrm{Na}$ outra secretaria especial está Ezequias Moreira que ficou famoso pelo caso da "sogra fantasma" - Veronica Durau, onde supostamente teria recebido salário como servidora fantasma da ALEP por mais de 10 anos. Denunciado pagou em dinheiro mais de 500 mil reais aos cofres públicos. Acompanha a família Richa desde 1970 na prefeitura de Londrina. Foi assessor de Beto Richa

\section{MUNICIPAL}

Em 28 de outubro de 2012, na ocasião da última eleição municipal da capital, o candidato do PDT, Gustavo Fruet foi eleito prefeito de Curitiba. De acordo com o Tribunal Superior Eleitoral (TSE), Fruet recebeu 597.200 votos, totalizando 60,65\% dos votos, Ratinho $\mathrm{Jr}^{12}$, por sua vez, recebeu 387.483 votos, totalizando 39,35\%. Ratinho Júnior é hoje o atual secretário de Desenvolvimento Urbano do Paraná do Governo Beto Richa. A pasta responsável pelas obras de infraestrutura dos municípios de todo o Estado é cobiçada pelas principais lideranças políticas do Estado. Em 2002, aos 21 anos, se filiou ao PSC e foi o deputado estadual mais votado, com 190 mil votos. Em 2006 se candidatou à Câmara federal pelo PPS e obteve 205,2 mil votos, a segunda maior votação do estado. Após dois mandatos como deputado federal, em 2010 Ratinho Júnior foi o

\footnotetext{
${ }^{12}$ Ratinho Jr é filho do radialista, apresentador empresário e ex vereador de Curitiba Carlos Massa, o Ratinho. A família é dona da rede de comunicação MASSA, o antigo SBT no Paraná. Nas últimas eleições Ratinho Junior já foi eleito o deputado estadual mais votado da história do Paraná. Em 2012, pediu licença do cargo na Câmara dos Deputados para concorrer à prefeitura de Curitiba ainda pelo PSC, com a coligação "Curitiba Criativa" (PSC, PCdoB, PR e PTdoB), perdendo no segundo turno para Gustavo Fruet (PDT). No ano seguinte, se aliou ao grupo político do governador Beto Richa (PSDB) - até então adversário - e assumiu a Secretaria de Desenvolvimento Urbano, uma das mais importantes no Estado.
} 
deputado estadual mais votado da história do Paraná com mais de 300 mil votos o que fez com que bancada da coligação do PSC passasse de 2 para 12 parlamentares. Recentemente, em março de 2016 Ratinho Junior, oficializou sua filiação ao Partido Social Democrático (PSD) como précandidato ao governo do estado em 2018.

\section{PODER LEGISLATIVO}

Nosso foco de análise é a Assembleia Legislativa do Estado do Paraná (ALEP) e o TRIBUNAL DE CONTAS que segundo o ordenamento do Estado é aparelho auxiliar da ALEP. A atual legislatura é composta por 54 deputados estaduais. Nas eleições de outubro de 2014 o Paraná registrou 7.861.171 de votos, sendo 5.756 .597 de votos válidos. Os eleitos seguem abaixo na tabela:

\begin{tabular}{|l|r|r|}
\hline CANDIDATO & \multicolumn{1}{l|}{$\%$} & VOTOS RECEBIDOS \\
\hline 20123 - RATINHO JUNIOR (PSC) & $5,23 \%$ & $300.928,00$ \\
\hline 15128 - ALEXANDRE CURI (PMDB) & $1,99 \%$ & $114.797,00$ \\
\hline 40123 - TIAGO AMARAL (PSB) & $1,50 \%$ & $86.390,00$ \\
\hline 15015 - ARTAGAO JUNIOR (PMDB) & $1,37 \%$ & $78.594,00$ \\
\hline 40590 - GILBERTO RIBEIRO (PSB) & $1,32 \%$ & $76.110,00$ \\
\hline 55669 - NEY LEPREVOST (PSD) & $1,24 \%$ & $71.470,00$ \\
\hline 20181 - PARANHOS (PSC) & $1,21 \%$ & $69.684,00$ \\
\hline 45789 - TRAIANO (PSDB) & $1,21 \%$ & $69.740,00$ \\
\hline 45456 - EVANDRO JUNIOR (PSDB) & $1,12 \%$ & $64.467,00$ \\
\hline 25110 - PLAUTO (DEM) & $1,11 \%$ & $63.959,00$ \\
\hline 25055 - PEDRO LUPION (DEM) & $1,10 \%$ & $63.580,00$ \\
\hline 33014 - DR. BATISTA (PMN) & $1,09 \%$ & $62.707,00$ \\
\hline 12000 - MARCIO PAULIKI (PDT) & $1,09 \%$ & $62.762,00$ \\
\hline 11223 - SCHIAVINATO (PP) & $1,07 \%$ & $61.507,00$ \\
\hline 45160 - PAULO LITRO (PSDB) & $1,06 \%$ & $60.918,00$ \\
\hline 15678 - ROMANELLI (PMDB) & $1,05 \%$ & $60.298,00$ \\
\hline 25155 - ELIO RUSCH (DEM) & $0,96 \%$ & $54.993,00$ \\
\hline 45745 - BERNARDO RIBAS CARLI (PSDB) & $0,96 \%$ & $55.481,00$ \\
\hline 23600 - DOUGLAS FABRICIO (PPS) & $0,95 \%$ & $54.518,00$ \\
\hline 45680 - FRANCISCO BUHRER (PSDB) & $0,88 \%$ & $50.757,00$ \\
\hline 55655 - CHICO BRASILEIRO (PSD) & $0,88 \%$ & $50.930,00$ \\
\hline 45655 - MAURO MORAES (PSDB) & $0,87 \%$ & $49.925,00$ \\
\hline 15151 - REQUIAO FILHO (PMDB) & $0,87 \%$ & $50.167,00$ \\
\hline 15190 - ANIBELLI NETO (PMDB) & $0,86 \%$ & $49.349,00$ \\
\hline 15178 - NEREU MOURA (PMDB) & $0,85 \%$ & $48.735,00$ \\
\hline 10123 - PASTOR EDSON PRACZYK (PRB) & $0,83 \%$ & $47.797,00$ \\
\hline
\end{tabular}




\begin{tabular}{|l|c|c|}
\hline 23043 - TERCILIO TURINI (PPS) & $0,82 \%$ & $47.023,00$ \\
\hline 20222 - GUTO SILVA (PSC) & $0,79 \%$ & $45.313,00$ \\
\hline 15115 - ADEMIR BIER (PMDB) & $0,79 \%$ & $45.699,00$ \\
\hline 11511 - MARIA VICTORIA (PP) & $0,78 \%$ & $44.870,00$ \\
\hline 20250 - MARCIO NUNES (PSC) & $0,78 \%$ & $45.105,00$ \\
\hline 45123 - CANTORA MARA LIMA (PSDB) & $0,76 \%$ & $43.549,00$ \\
\hline 17800 - ADELINO RIBEIRO (PSL) & $0,75 \%$ & $42.924,00$ \\
\hline 25111 - NELSON JUSTUS (DEM) & $0,75 \%$ & $43.446,00$ \\
\hline 13013 - PROFESSOR LEMOS (PT) & $0,74 \%$ & $42.374,00$ \\
\hline 13131 - TADEU VENERI (PT) & $0,73 \%$ & $42.206,00$ \\
\hline 13115 - PÉRICLES DE HOLLEBEN MELLO (PT) & $0,71 \%$ & $40.966,00$ \\
\hline 15250 - JONAS GUIMARAES (PMDB) & $0,70 \%$ & $40.139,00$ \\
\hline 20888 - PALOZI (PSC) & $0,68 \%$ & $39.364,00$ \\
\hline 12680 - NELSON LUERSEN (PDT) & $0,65 \%$ & $37.316,00$ \\
\hline 12612 - ANDRE BUENO (PDT) & $0,63 \%$ & $36.506,00$ \\
\hline 77777 - FELIPE FRANCISCHINI (SD) & $0,62 \%$ & $35.842,00$ \\
\hline 12012 - FERNANDO SCANAVACA (PDT) & $0,62 \%$ & $35.905,00$ \\
\hline 20044 - GILSON DE SOUZA (PSC) & $0,60 \%$ & $34.470,00$ \\
\hline 14789 - TIÃO MEDEIROS (PTB) & $0,55 \%$ & $31.875,00$ \\
\hline 20410 - COBRA REPORTER (PSC) & $0,51 \%$ & $29.097,00$ \\
\hline 20111 - CLAUDIA PEREIRA (PSC) & $0,51 \%$ & $29.379,00$ \\
\hline 20088 - HUSSEIN BAKRI (PSC) & $0,46 \%$ & $26.682,00$ \\
\hline 20012 - WILMAR REICHEMBACH (PSC) & $0,44 \%$ & $25.452,00$ \\
\hline 54100 - MARCIO PACHECO (PPL) & $0,43 \%$ & $24.855,00$ \\
\hline 20120 - ALEXANDRE GUIMARÃES (PSC) & $0,42 \%$ & $24.357,00$ \\
\hline 20777 - MISSIONÁRIO RICARDO ARRUDA (PSC) & $23.592,00$ \\
\hline 43123 - RASCA RODRIGUES (PV) & $0,41 \%$ & $23.815,00$ \\
\hline
\end{tabular}

Uma análise mais despretensiosa do resultado das eleições de 2014 pode atestar um certo grau de renovação dos deputados eleitos para a atual legislatura, tendo em vista que dos 54 deputados estaduais eleitos 21 são novos em relação a legislatura anterior (39\% do total - azul), mas estudaremos mais a fundo os casos. Ao analisarmos suas trajetórias políticas e principalmente suas genealogias/famílias veremos que nada menos que 8 desses 21 deputados são herdeiros políticos (38\%). Corroborando assim nossa idéia de que a família importa. A importância se dá em várias esferas essenciais da vida política: entre elas o do sucesso/viabilidade eleitoral.

O estudo de Tiago Valenciano teve o objetivo de "demonstrar como o nepotismo é um sistema político que reproduz novos líderes a partir dele mesmo, se auto reproduzindo e se reinventando a cada eleição" (VALENCIANO, 2015 p. 141). O estudo dos resulto das eleições de 2002, 20062010 e 2014 constata que o número de herdeiros políticos vem aumentando no Paraná. 


\section{A BANCADA DOS JUNIOR(ES)}

As eleições de 2014 configuraram um fato ilustrativo/determinante a nossa análise: $\mathrm{Na}$ ALEP a maior bancada para a próxima legislatura não é de nenhum dos partidos políticos registrados perante a Justiça Eleitoral. Mesmo a maior bancada partidária, a do PSC, que elegeu 12 deputados, perde em número de eleitos para a bancada informal, a "Bancada dos Junior(es)", composta por 15 deputados eleitos que possuem antecessores com histórico na política local.

A bancada dos juniores é formada pelos 8 novatos: Alexandre Guimarães (PSC) - filho do prefeito de Campo Largo, Affonso Guimarães; Claudia Pereira (PSC) - esposa do ex-deputado estadual e atual prefeito e Foz do Iguaçu, Reni Pereira; Felipe Francischini (SD) - filho do deputado federal Fernando Francischini; Maria Victória (PP) - filha da deputada federal e vice-governadora eleita Cida Borghetti, e filha do deputado federal eleito Ricardo Barros; Paulo Litro (PSDB) - filho da deputada estadual Rose Litro, e do ex-deputado estadual Luiz Litro; Requião Filho (PMDB) filho do senador e ex-governador do Paraná por três mandatos, Roberto Requião;Tiago Amaral (PSB) - filho do ex-deputado e atual conselheiro do Tribunal de Contas do Estado Durval Amaral.

Os novatos herdeiros políticos se juntam aos outros 7 companheiros de familismo/nepotismo Alexandre Curi (PMDB) - neto do ex-presidente da Alep, Aníbal Khury; André Bueno (PDT) filho do ex-deputado e atual prefeito de Cascavel, Edgar Bueno; Anibelli Neto (PMDB) - filho do ex-deputado Antônio Martins Anibelli, e neto do também ex-parlamentar Antônio Anibelli; Artagão Júnior (PMDB) - filho do ex-deputado e atual presidente do Tribunal de Contas do Estado do Paraná, Artagão de Mattos Leão; Bernardo Ribas Carli (PSDB) - filho do ex-prefeito de Guarapuava Luiz Fernando Ribas Carli, e irmão do ex-deputado estadual Luiz Fernando Ribas Carli Filho; Evandro Júnior (PSDB) - sobrinho do atual deputado estadual Hermas Brandão Filho, e neto do ex-presidente da Alep Hermas Brandão; Pedro Lupion (DEM) - filho do deputado federal Abelardo Lupion.

A soma dos novatos herdeiros com os já "experientes" deputados estaduais herdeiros com tradição familiar daria uma bancada de 15 deputados. Se criássemos uma bancada “ de Juniore(es), das famílias tradicionais e/ou do nepotismo“, essa seria a maior bancada de deputados da ALEP.

Se fizermos um exercício especulativo e pensarmos em orçamentos, caso a ALEP fosse uma cidade, ela seria a $9^{\circ}$ cidade mais importante do Paraná. O que estamos afirmando é que o orçamento da ALEP é maior que os orçamentos das outras 390 cidades do Estado. Vale lembrar que a ALEP ocupa um espaço de um quarteirão do centro cívico de Curitiba e tem um prédio/órgão auxiliar que é o Tribunal de Contas. Pois bem, esse robusto orçamento e suas respectivas ações são 
conduzidos pelo seu presidente, atualmente o presidente da ALEP é o deputado estadual Ademar Luiz Traiano (PSDB). O segundo cargo mais importante da Casa é o primeiro secretário (responsável pelas contratações de funcionários, prestações de serviço, entre outras atividades vitais da casa). O posto é ocupado por Plauto Miro Guimarães (DEM) - nascido em Ponta Grossa/PR em 1963. É neto do senador Flávio Carvalho Guimarães e seu pai, Plauto Miró Guimarães foi prefeito de Ponta Grossa e Secretario de Estado de Interior e Justiça nos anos 60.

O campeão de votos das eleições de 2014 foi Ratinho Junior (atual secretário de Estado de Beto Richa e filho do comunicador e também ex vereador Carlos Massa - o Ratinho). Apesar de novato/estrenate como deputado estadual, Ratinho Jr. já fora deputado federal por duas vezes. Nas eleições de 2014 recebeu mais de 300 mil votos, levando consigo mais 12 deputados do PSC, formando a maior bancada na ALEP. Com a expressiva votação Ratinho Jr desbancou o até então sempre campeão de votos Alexandre Curi (PMDB). Muitos consideram Ratinho Jr, virtual candidato ao Governo do Paraná para as eleições de 2018.

Alexandre Curi foi o segundo deputado estadual mais votado da Casa com mais de 100 mil votos. Curi é neto de Anibal Curi nome que dá nome ao prédio da ALEP. Quando dos escândalos revelados pela série de reportagens da Gazeta do Povo/RPC chamada "Diários Secretos" onde constatou-se o emprego de centenas de funcionários fantasma, ele era o primeiro secretário da Casa. $^{13}$

O terceiro deputado estadual mais votado foi o estreante/novato Tiago Amaral, de apenas 28 anos, filho do ex deputado e atual conselheiro do Tribunal de Contas - Durval Amaral. Tiago Amaral aparece nos jornais pela expressiva votação para um estreante na vida pública e também pelas delações da operação Publicano. "Luiz Antônio de Souza contou no depoimento que Durval Amaral, conselheiro do Tribunal de Contas do Estado do Paraná (TCE-PR), procurou o grupo da Receita em Londrina, no norte do estado, e pediu $R \$ 200$ mil para a campanha do filho, Tiago Amaral, que disputava uma vaga na Assembleia Legislativa do Paraná. Ainda segundo o auditor, Durval Amaral sabia que era dinheiro de propina. Diante do juiz, o auditor disse que a corrupção na Receita era institucionalizada e envolvia de $80 \%$ a $90 \%$ dos servidores do órgão. O auditor entrou na receita em 1985 por concurso e, segundo ele, naquela época já havia acertos. Conforme

\footnotetext{
${ }^{13}$ Das 33 pessoas presas inicialmente, apenas quatro ex-diretores da Alep foram condenados. Abib Miguel, Claudio Marques da Silva, José Ary Nassiff e Daor Marins de Oliveira. Todos receberam penas acima de 18 anos de prisão em primeira instância, mas apenas Daor não conseguiu o benefício de recorrer da decisão em liberdade. Já os deputados Nelson Justus (DEM) e Alexandre Curi (PMDB), que comandavam a Alep na época das nomeações foram processados por improbidade administrativa. Porém, os processos contra os dois ainda não foram julgados e ambos ainda mantêm os mandatos na ALEP. http://g1.globo.com/pr/parana/noticia/2014/03/depois-de-4-anos-processos-dos-diarios-secretosesperam-julgamento.html Acesso em 10.04.2016.
} 
as investigações, o dinheiro de propina enriqueceu auditores corruptos e financiou campanhas eleitorais"14

\section{PODER JUDICIÁRIO}

O Poder Judiciário e o Ministério Público também podem representar instituições atravessadas por interesses e conexões entre famílias e demais poderes. Estudos recentes (ALMEIDA, 2014; KAMINSKI, 2014) indicam que o poder judiciário opera no mesmo modus operandi que trabalhamos até aqui. Atualmente o Paraná, dentro do Poder Judiciário há grande ênfase nas conexões entre famílias tradicionais e históricas e os demais poderes do Estado. Assim como os poderes executivo e legislativo - tribunais de contas, o judiciário, ministério público, cartórios e as mídias/setores empresarias revelam grandes redes de interesse e nepotismo organizado dentro do Estado.

\section{CONSIDERAÇÕES FINAIS}

As conexões entre famílias e instituições políticas são tema de uma série de estudos que visam sistematizar dados/informações e criticar sua persistência/pertinência ao funcionamento do Estado. Tendo em vista os princípios da impessoalidade e da moderna burocracia criticamos as ligações em enorme escala e muitas vezes de poucos e constantes (seculares) nome/genealogias presentes entre os poderes. Foi James Madison que em um dos famosos "Artigos Federalistas"15 deixou bem claro os motivos da rigorosa adoção dos princípios da separação dos poderes: “o acúmulo de todos os poderes: legislativo, executivo e judiciário nas mãos de mesmas pessoas, seja de uma pessoa, de algumas ou de muitas, seja hereditário, autodesignado ou eletivo, pode ser justamente considerado a própria definição de Tirania”. (MADISON, 1993). Acreditamos que após a análise e constatação de nossas pesquisas e dados questionamentos importantes ao funcionamento efetivo do Estado devem ser feitos, tais como: Como pode um tio de deputado aliado ao chefe do poder executivo ser o conselheiro que irá julgar as contas do Governador? Como podem deputados

\footnotetext{
14 Ver mais em http://g1.globo.com/pr/parana/operacao-publicano/noticia/2016/03/delator-reafirma-que-propinafinanciou-campanhas-eleitorais-no-parana.html. Acesso em 15.04.2016

${ }^{15}$ Escritos para tentar convencer os cidadãos a votar favoravelmente ao novo texto constitucional de então. 
estaduais ficarem isentos de uma de suas duas prerrogativas básicas - fiscalizar as ações do Poder Executivo sendo que por diversas vezes são eles mesmos parentes do mesmo? Como pode o chefe do Poder Executivo nomear irmão e esposa para trabalhar em pastas fundamentais ao desenvolvimento das políticas públicas do Estado? Como pode o Poder Judiciário ter em seu corpo técnico pessoas ligadas aos processos que estavam/estão/estarão julgados, em julgamento ou a ser julgado. Há a necessidade do elevado número de cargos comissionados e de seus altos salários para o elaboração e manutenção de políticas públicas?

Pois bem, o conceito de nepotismo é neste artigo entendido e usado dentro do entendimento de Adam Below: "Parentesco mais estado é igual a Nepotismo" (BELLOW, 1996, p.39) e se torna ilustrativo de a razão. A literatura especializada indica uma das características da ação social e econômica dos poderosos fundamenta-se em torno do aparelho de Estado, como forma direta e indireta de controles do fluxo de informações, capitais e privilégios essenciais para a reprodução ampliada da classe dominante. O mesmo vale em outro sentido: a pobreza, a carência e a miséria também podem ser consideradas produtos da falta de políticas sociais do Estado. Pobreza e riqueza, poder e carência são diferentes lados da mesma moeda social, econômica e política. Buscamos com esse artigo elucidar esse debate, trazer o foco ao momento atual e ao Estado do Paraná, que por muitas vezes é enunciado como modelo de moderna administração. Desnaturalizar algumas tradições, costumes, ações, leis, entre outras é tarefa básica da ciência social. Pensamos que com esse artigo contribuímos para esse debate e desde já lançamos o desafio para que essa agenda de pesquisa seja permanentemente colocada, estudada e aperfeiçoada, que possa inclusive superar e modernizar tais procedimentos, entendimentos e tradições, se não superar que pelo menos se iguale aos passos e moldes do que a classe dominante faz em relação a sua própria perpetuação no poder.

\section{REFERÊNCIAS}

FREYRE, Gilberto. Casa-Grande \& Senzala, 50ª edição. Global Editora. 2005.

HOLANDA, Sérgio Buarque de. Raízes do Brasil. Raízes do Brasil. 8. ed. Rio de Janeiro: José Olympio, 1969.

FAORO, Raimundo. Os donos do poder. Formação do patronato político brasileiro. Porto Alegre; Rio de Janeiro: Globo, 1985.

NEGRÃO, Francisco. Genealogia Paranaense. Vol.1, Curitiba: Imprensa Paranaense S.A., 1926. 
OLIVEIRA, Ricardo Costa de. Na Teia do Nepotismo. Sociologia Política das relações de

parentesco e poder político no Paraná e no Brasil. Insight. 2012.

. O Silêncio dos Vencedores : genealogia, classe dominante

e Estado no Paraná. Moinho do Verbo Editora. 2001.

KAMINSKI. Henry Levy. Elites e parentesco no sistema judicial paranaense. Dissertação de

Mestrado em Sociologia. Universidade Federal do Paraná. 2013.

MADISON, James; HAMILTON, Alexander; JAY, John. Os Artigos Federalistas. Apresentação:

Isaac Kramnick; tradução de Maria Luiza X. de A. Borges. Rio de Janeiro: Nova Fronteira, 1993.

\title{
A BENCH OF JUNIOR(S): FAMILIES AND RELATIONSHIP IN LEGISLATURE PARANAENSE DURING THE GOVERNMENT BETO RICHA
}

\begin{abstract}
We investigate the structure of power and their political agents materialized in the identification of family relationships and occupation of strategic positions within the Government of Paraná, especially in the departments of State and the Legislative Assembly of Paraná. In this sense, we tried to explain the relationships of interest involving mainly parliamentary and political positions in the state apparatus (executive, legislative and judicial), seeking to secure advantages and privileges (social, economic and electoral) for these participants. Through the sociological profile analysis, the political trajectories and positions occupied by the actors and electoral data in order to identify / highlight situations of privilege with respect to kinship and occupying strategic positions within the state apparatus. Finally, we analyze the trajectories and connections between the families of the main actors involved in this complex web of interests and redeem the historical origins of these developments.
\end{abstract}

Key-words: Kinship, Paraná, Parliamentarians 